УДК 661.63.001

\title{
ЭНЕРГОЭФФЕКТИВНОСТЬ КОМПЛЕКСНЫХ ТЕХНОЛОГИЙ КОНВЕРСИИ ФОСФОГИПСА
}

\author{
(C) 2013 г. Л. Л. Товажнянский, В. П. Мешалкин*, П. А. Капустенко, С. И. Бухкало, \\ О. П. Арсеньева, А. Ю. Перевертайленко \\ Национальный технический университет "Харьковский \\ политехнический институт” \\ *Российский химико-технологический университет им. Д.И. Менделеева, Москва \\ bis.khr@gmail.com \\ Поступила в редакцию 14.09.2012 г.
}

\begin{abstract}
Представлены возможности повышения энергоэффективности технологий комплексной конверсии фосфогипса. Приведены основные направления получения целевых продуктов. Предложена классификация технологии конверсии фосфогипса по уровню энергозатрат. Предложены основные варианты разработки энергосберегающих технологий конверсии фосфогипса с применением методов интеграции тепловых процессов и современного теплоэнергетического оборудования.
\end{abstract}

DOI: $10.7868 / \mathrm{S} 0040357113030147$

\section{ВВЕДЕНИЕ}

Главной проблемой отрасли производства фосфорсодержащих удобрений в целом является образование многотоннажного и весьма обременительного отхода - фосфогипса. Количество фосфогипса, только получаемого в качестве отхода производства экстракционной фосфорной кислоты и отправляемого в отвалы, превышает мировую добычу природного гипса. Так, капиталовложения в создание отвалов фосфогипса на грунте с системой рециркуляции воды могут достигать около $8 \%$ капиталовложений в производство фосфорной кислоты, а эксплуатационные затраты на содержание таких отвалов фосфогипса могут достигать $3.9 \%$ общих эксплуатационных затрат производства [1].

Отрасль производства фосфорсодержащих удобрений за последние годы снизила объемы производства. Так, например, Украина оказалась перед угрозой полного исчезновения в грунтах доступных форм фосфатов, которые были накоплены за годы интенсивной химизации. Так, уменьшение доз внесения фосфорных удобрений на $80 \%$ по сравнению с 1990 г. привело к снижению средневзвешенного содержимого подвижного фосфора в грунтах за последние 10 лет на $1.1-$ 1.4 мг [2]. Эффективность сельскохозяйственного производства зависит от своевременного внесения необходимого количества минеральных удобрений для компенсации потери с урожаем действующего вещества. На Украине площадь пашни с низким и средним содержанием подвижного фосфора составляет почти 57\% общей площади [3].
Именно за счет низкой обеспеченности грунтов в настоящее время доступным для растений фосфором окупаемость фосфорных удобрений может быть довольно высокой, так как в среднем 1 кг $\mathrm{P}_{2} \mathrm{O}_{5}$ обеспечивает прирост 4-5 кг зерна или 3040 кг корней сахарной свеклы. Технологические схемы, используемые для получения удобрений из фосфатного сырья, базируются, главным образом, на разложении обогащенного материала кислотой или смесью кислот. При применении наиболее широко распространенного сернокислотного метода вскрытия апатита (рис. 1) из сырья извлекается около 94\% фосфора, 10-20\% фтора в соединениях и часть образующегося фосфогипса.

Основными препятствиями для конверсии фосфогипса являются следующие его свойства: радиоактивность и наличие примесей $\left(\mathrm{P}_{2} \mathrm{O}_{5}\right.$ в растворимой, сокристаллизованной формах, соединения фтора, $\mathrm{SiO}_{2}, \mathrm{Al}_{2} \mathrm{O}_{3}, \mathrm{Fe}_{2} \mathrm{O}_{3}, \mathrm{Na}_{2} \mathrm{O}$, органические вещества). Нерадиоактивным фосфогипсом, который можно применять для производства стройматериалов, считают фосфогипс, в котором содержание радия не превышает 10 пКи/г [2].

Создание и внедрение эффективных технологий переработки фосфогипса поможет решить проблему утилизации и переработки гипса, образующегося в качестве отхода в других производствах. В комплексных технологиях конверсии фосфогипса имеют место стадии высокотемпературной обработки материалов. Так, в производстве сульфата аммония, строительного мела и концентратов редкоземельных элементов обжигу 


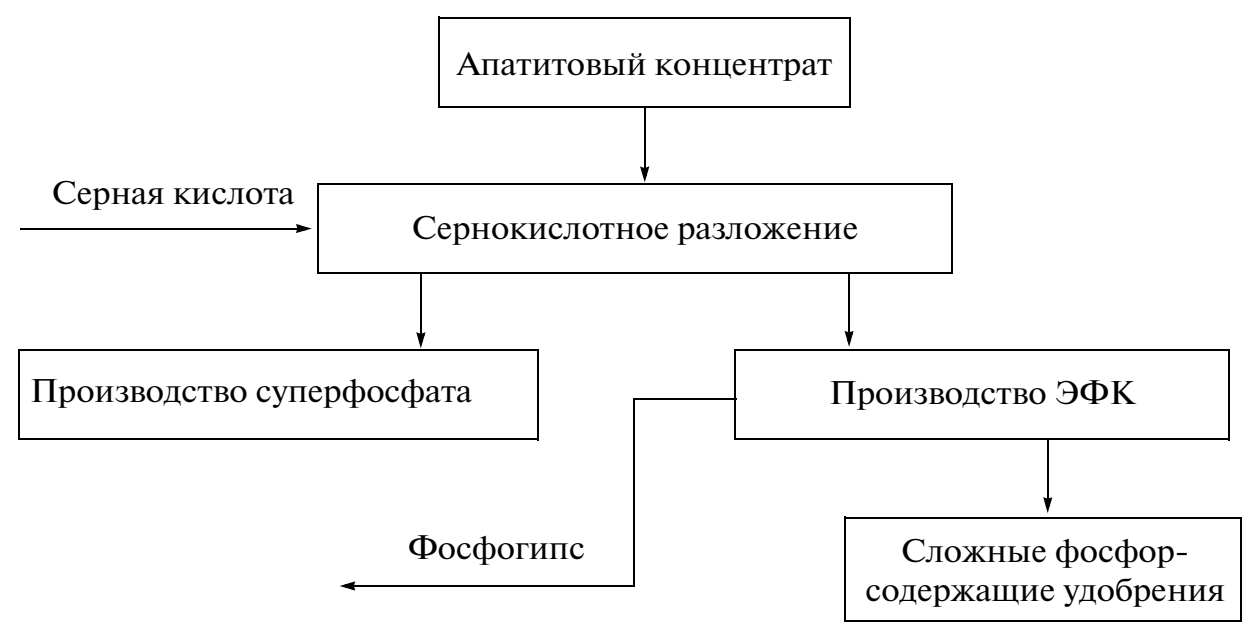

Рис. 1. Упрощенная функциональная схема сернокислотного разложения фосфорсодержащего сырья: ЭФК - эКстракционная фосфорная кислота.

подвергается карбонат кальция, в результате чего получается окись кальция, принимающая участие в ряде химических реакций.

Целью исследования также является формирование общих подходов к созданию безотходных комплексных производств, основные принципы которых можно сформулировать следующим образом:

разработка энерготехнологических схем, предусматривающих полную переработку сырья и побочных продуктов в полезные продукты - принцип рационального использования всех компонентов сырья и энергии, с использованием вторичных энергоресурсов на базе принципов рециркуляции и цикличности;

принцип максимальной изолированности производства от окружающей среды - количество образующихся отходов вредных веществ в воздушном бассейне, почве и водоемах меньше их допустимых концентраций;

принцип круговорота веществ и энергии за исключением сырья и целевых продуктов;

принцип комплексного использования многокомпонентного сырья в безотходном производстве, побочная продукция приобретает все свойства целевой продукции, сырье используется в полном объеме и расширяется ассортимент продукции и др.

Следует отметить, что технологические комплексы могут создаваться разных масштабов с учетом материало- и энергоемкости выпускаемой продукции, экономического, экологического, социального, правового и других факторов. Несмотря на большое число предложений по разработке технологических процессов конверсии фосфогипса в мировой практике, степень его утилизации все еще остается низкой. Это связано, прежде всего, с тем, что большинство авторов разработок подразделяют процессы конверсии фосфогипса на две группы, которые не учитывают современные энергосберегающие и экологические требования: 1) не требующие предварительной обработки фосфогипса перед использованием; 2) термическое разложение фосфогипса. Направления развития вышеизложенных задач и принципов в области получения продуктов химической технологии можно разделить на два принципиально различных пути реализации: 1) реконструкция и модернизация действующих производств; 2) создание новых безотходных или малоотходных комплексов. Первый путь неперспективен, так как не решает вопрос кардинально, второй путь более радикальный и экономичный.

\section{ОСНОВНАЯ ЧАСТЬ}

При выборе способа удаления и хранения фосфогипса, на наш взгляд, для вновь сооружаемых предприятий следует учитывать не только конкретные условия региона, возможности промышленной площадки и технологические особенности переработки сырья, но и возможность создания безотходных энерго- и экономически эффективных комплексов по переработке фосфатного сырья, и фосфогипса в частности, в целевые продукты (рис. 2). Наибольший эффект по повышению энергоэффективности технологических систем процессов конверсии фосфогипса может быть достигнут при оптимальной тепловой интеграции таких технологических систем в производственный комплекс фосфорсодержащих удобрений. Такая интеграция предполагает использование широкого спектра теплоэнергетического оборудования: котлов-утилизаторов, турбин, теплообменников “высокотемпературные газы/воздух”, теплообменников для нагрева твердых частиц в псевдоожиженном слое, теплообменников “пар/вода" и т.д. 


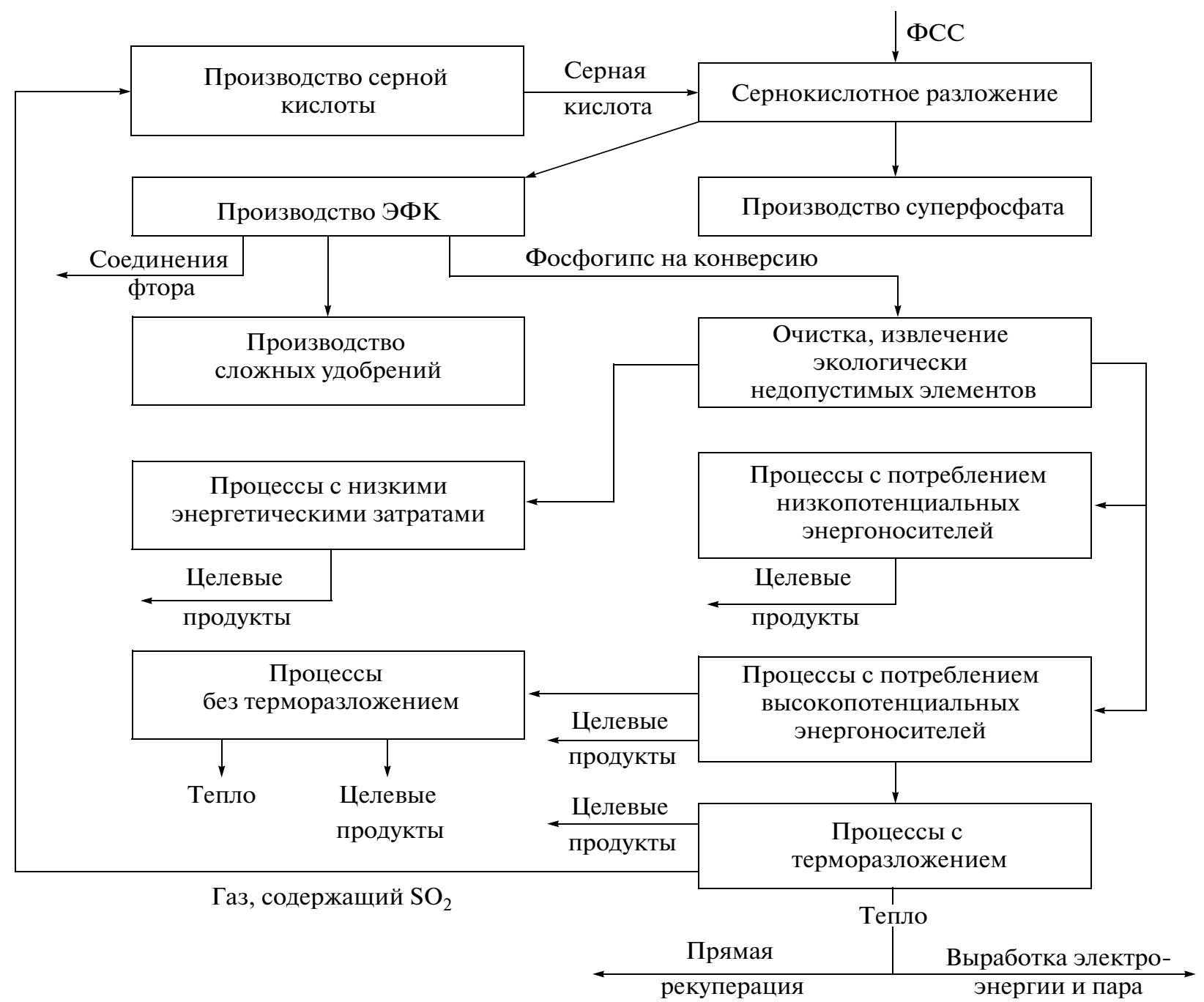

Рис. 2. Функциональная схема комплексной переработки фосфорсодержашего сырья (ФСС).

Технология комплексной переработки фосфогипса, предлагаемая нами (рис. 2), включает в себя предварительную очистку фосфогипса и извлечение из него экологически вредных элементов. Процессы характеризуются различными энергетическими затратами в зависимости от получаемых целевых продуктов: гипс для химической мелиорации почв, гипсовые вяжущие в виде $\alpha$-полугидрата, гипсовые вяжущие в виде $\beta$-полугидрата, серная кислота, цемент, сульфат натрия, сульфат аммония, карбонат кальция, окислы или соли редкоземельных элементов, углекислый стронций и др.

В настоящее время именно технологии конверсии фосфогипса могут кардинально решить проблему его более или менее полного использования. Однако здесь возникает еще одно существенное препятствие в конверсии фосфогипса рост цен на энергоносители. Следовательно, технологии конверсии фосфогипса должны быть, прежде всего, энергоэффективными. Концепции повышения энергоэффективности вышеупомянутых технологий связаны с тремя основными факторами: 1) повышение эффективности процессов самой технологии; 2) интеграция отдельных технологических процессов в производственный комплекс, желательно, безотходный; 3) организация правильного выбора эффективного и надежного теплообменного оборудования.

Примером реализации концепции, связанной с первым фактором, может служить процесс получения серной кислоты и цементного клинкера. Подобная схема рекуперации тепла может быть применена и в производстве обжиговых вяжущих, где тепло отходящих газов может быть использовано для подогрева воздуха, поступающего на стадию обжига.

Интеграция технологической системы конверсии фосфогипса в состав производственного комплекса фосфорсодержащих удобрений предполагает функционирование этой системы вме- 


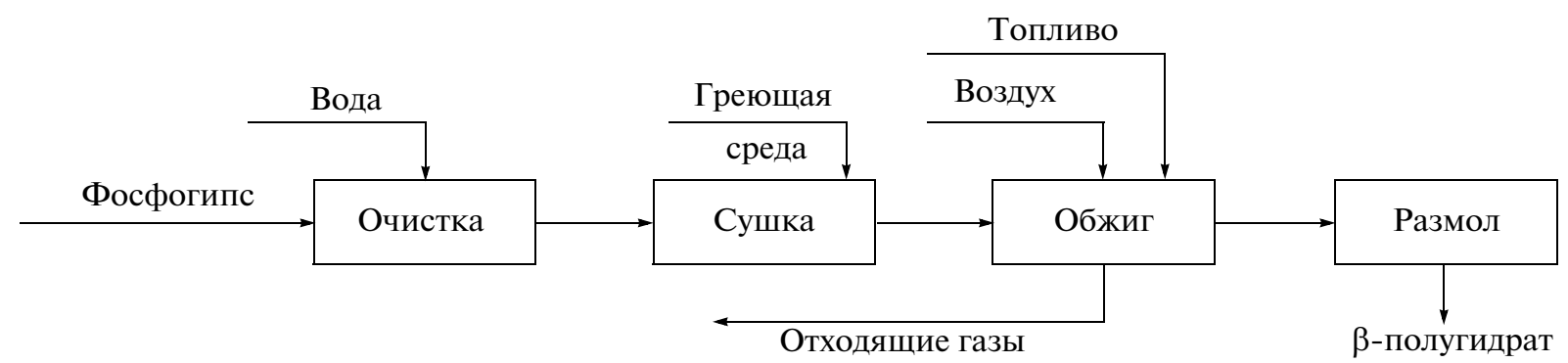

Рис. 3. Функциональная схема производства обжиговых вяжущих с потреблением высокопотенциальных энергоносителей.

сте с другими химико-технологическими системами производственного комплекса. Эффективно использовать энергетические ресурсы в таких комплексах позволяют специальные методы интеграции тепловых процессов [4-8]. Если количество энергии, выработанной технологической системой, превосходит потребности самой системы, то энергия может быть экспортирована в другую систему и, наоборот, если имеется потребность, она может быть импортирована из другой системы комплекса. Примером реализации подобной концепции может служить технология производства из фосфогипса серной кислоты и агломерата.

Последовательности чередующихся нагревов и охлаждений на всех этапах производства, от первичной переработки сырья до получения конечного продукта, требуют широкого использования теплообменников и интеграции потоков. В этой связи выбор эффективного теплообменного оборудования для нагрева, охлаждения и рекуперации имеет первостепенное значение для экономичной работы всего производства в целом.

Классификация процессов конверсии фосфогипса по уровню энергозатрат позволяет их разделить на три основные группы: 1) низкие энергозатраты; 2) энергозатраты с потреблением низкопотенциальных энергоносителей; 3) энергозатраты с потреблением высокопотенциальных энергоносителей (топливоемкие).

К процессам первой группы относится, прежде всего, применение фосфогипса в сельском хозяйстве. Здесь, в крайнем случае, энергозатраты связаны со снижением уровня радиоактивности фосфогипса или его очисткой. К энергозатратным с потреблением низкопотенциальных энергоносителей относятся, например, процессы производства автоклавных гипсовых вяжущих ( $\alpha$-полугидрата).

К энергозатратным с потреблением высокопотенциальных энергоносителей (сжигаемого топлива) относятся процессы производства обжиговых вяжущих ( $\beta$-полугидрата) и некоторые технологии комплексной переработки фосфогипса: получение цементного клинкера и серной кисло- ты, сульфата аммония, мела и концентрата редкоземельных элементов, серной кислоты и агломерата для дорожного строительства, серной кислоты и извести, а также другие $[9,10]$. Проведенный анализ процессов производства обжиговых вяжущих позволяет составить обобщенную функциональную схему производства (рис. 3).

В комплексных технологиях конверсии фосфогипса также имеет место стадия высокотемпературной обработки материалов. Так, в производстве сульфата аммония, строительного мела и концентратов редкоземельных элементов обжигу подвергается карбонат кальция, в результате чего получается окись кальция, принимающая участие в ряде химических реакций.

Например, такие технологии, как совместное получение серной кислоты и строительных материалов (цементного клинкера или агломерата для дорожного строительства) включают в себя процессы термического разложения фосфогипса, проходящие при очень высоких температурах, достигающих $900-1200^{\circ} \mathrm{C}$ (рис. 4).

Учитывая то, что для производства вяжущих в промышленных масштабах применяется, в основном, $\beta$-полугидрат, можно сказать, что рассмотренные технологии конверсии фосфогипса являются энергозатратными с потреблением высокопотенциальных энергоносителей, т.е. требуют сжигания топлива для проведения соответствующих процессов.

В настоящее время именно технологии конверсии фосфогипса, отнесенные к третьей группе по энергозатратности, могут кардинально решить проблему его более или менее полного использования. Следовательно, технологии конверсии фосфогипса должны быть, прежде всего, энергоэффективными. Концепции повышения энергоэффективности вышеупомянутых технологий, на наш взгляд, могут быть связаны со следующими основными особенностями проведения конверсии: 1) повышение эффективности процессов самой технологии; 2) интеграция отдельных технологических процессов в производственный комплекс, желательно, безотходный; 3) организация 


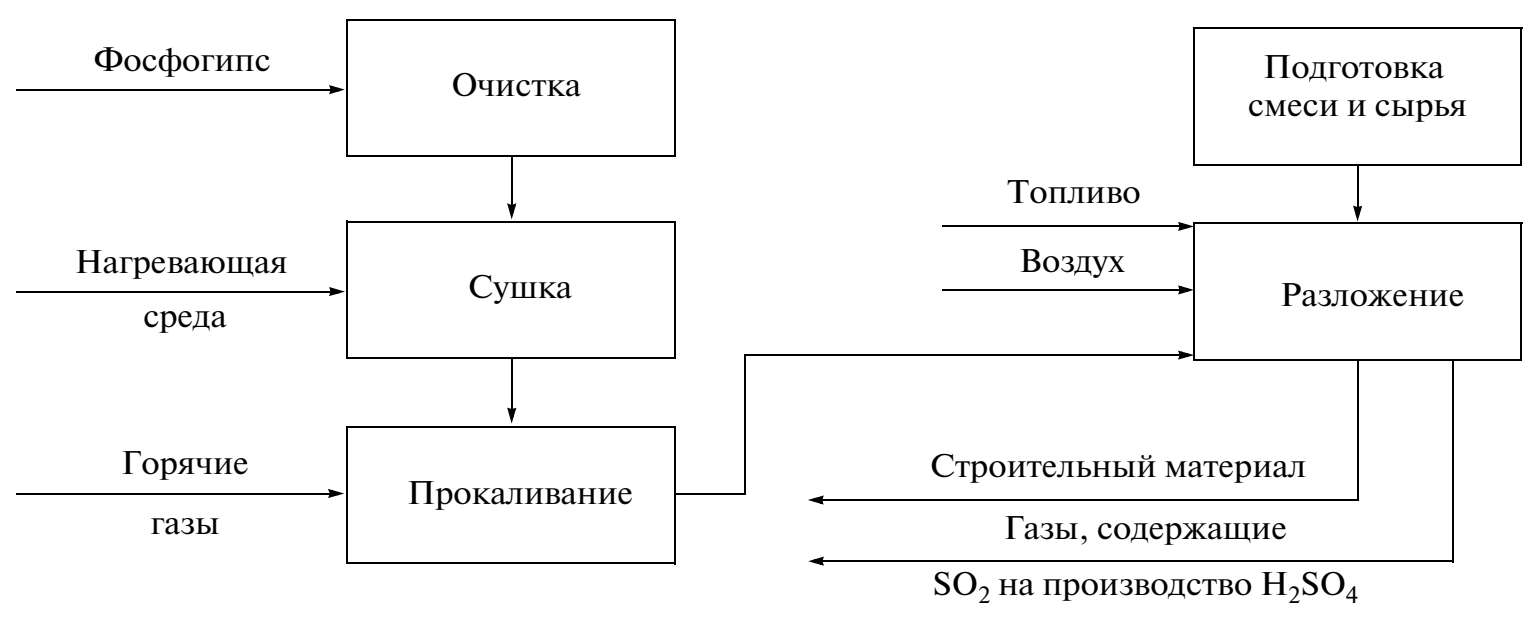

Рис. 4. Функциональная схема конверсии фосфогипса с применением стадии термического разложения.

правильного выбора эффективного и надежного теплообменного оборудования.

Примером реализации первой концепции может служить процесс получения серной кислоты и цементного клинкера, разработанный компаниями Lurgi G.m.b.H и Babcock-BSH (Германия). Для разложения фосфогипса был предложен реактор с циркулирующим кипящим слоем, температура циркулирующего кипящего слоя составляла $950-1100^{\circ} \mathrm{C}$. Отходящими горячими газами реактора осуществлялся непрямой нагрев сырьевой смеси в противоточной вращающейся печи до $450^{\circ} \mathrm{C}$. Отходящие газы из печи с температурой 200-250 ${ }^{\circ} \mathrm{C}$ использовались как греющая среда в сушилке сырьевой смеси. Такая каскадная противоточная схема рекуперации отходящих горячих газов из реактора разложения позволила снизить расход тепла на $30 \%$ по сравнению с процессами разложения фосфогипса, которые применялись в промышленности в конце 1960-х-начале 1970-х годов. Подобная схема рекуперации тепла может быть применена и в производстве обжиговых вяжущих ( $\beta$-полугидрата), где тепло отходящих газов может быть использовано для подогрева воздуха, поступающего на стадию обжига.

Интеграция технологической системы конверсии фосфогипса в состав производственного комплекса фосфорсодержащих удобрений предполагает функционирование этой системы вместе с другими химико-технологическими системами производственного комплекса. Эффективно использовать энергетические ресурсы в таких комплексах позволяют специальные методы интеграции тепловых процессов. Энергоносители, подводящие тепловую энергию к химико-технологическим системам (XTC), выработанную из соответствующих топливных ресурсов, являются горячими теплоносителями ХТС. Для функционирования ХТС необходимо и охлаждение технологических потоков. Охлаждение (отвод тепла) производится потоками от источника холода (ресурс охлаждающей воды, холодильные установки, ресурс воздушного охлаждения и т.п.), которые являются холодными теплоносителями или холодными внешними потоками ХТС. Использование тепла технологических потоков (исходных, целевых, промежуточных и побочных продуктов) данной ХТС является рекуперацией тепла технологических потоков. Если количество энергии, выработанной технологической системой, превосходит потребности самой системы, то энергия может быть экспортирована в другую систему и, наоборот, если имеется потребность, она может быть импортирована из другой системы комплекса. Примером реализации подобной концепции может служить технология производства из фосфогипса серной кислоты и агломерата, который может быть использован в дорожном строительстве. Технология разработана Флоридским институтом исследования фосфатов и компанией Davy McKee Ltd. (США). В этой технологии тепло отходящих газов предусмотрено использовать для получения пара и электроэнергии, излишки которых можно экспортировать за пределы производства. Тепло отходящих газов может быть также использовано на подогрев воды для теплоснабжения помещений производственного комплекса и/или прилегающих к комплексу жилых районов.

Последовательности чередующихся нагревов и охлаждений на всех этапах производства, от первичной переработки сырья до получения конечного продукта, требуют широкого использования теплообменников и интеграции потоков. В этой связи выбор эффективного теплообменного оборудования для нагрева, охлаждения и рекуперации имеет первостепенное значение для экономичной работы всего производства в целом. Существующая в настоящее время тенденция замены устаревшего кожухотрубного теплообменного оборудования на высокоэффективные пластин- 
чатые теплообменные аппараты показала, что такая замена приводит к существенной экономии средств в процессе эксплуатации, а также упрощает обслуживание и переналадку [11-13].

Организация производства направлена не только на утилизацию всех побочных продуктов, но и на использование всего выделяемого тепла, как внутри данной системы, так и частично в соседних взаимосвязанных экологических подсистемах. Следовательно, основные задачи в области ресурсо- и энергосбережения для данной химической технологии можно сформулировать следующим образом:

разработка малоотходных или безотходных технологий;

определение перечня и количества продуктов, которые могут быть усвоены природными биологическими системами;

создание предприятий комплексной переработки сырья, которые используют фактически полностью отходы и выбросы своего производства, а также производств других отраслей промышленности;

создание малоэнергоемких производств с минимальным потреблением воды;

модернизация и совершенствование теплообменного оборудования в процессе проектирования новых технологий;

повышение уровня регенерации тепла потоков и на этой базе широкое использование энерготехнологических схем и др.

Создание таких технологий позволяет решать две взаимосвязанные задачи: экологическую, с учетом ресурсо- и энергосбережения, и экономическую, с учетом социальной эффективности, что позволяет интенсивно развивать отрасли промышленности.

\section{ЗАКЛЮЧЕНИЕ}

Реализация энергосберегающих мероприятий конверсии фосфогипса в сочетании с тепловой интеграцией технологических систем производственных комплексов фосфорсодержащих удобрений позволяет превратить фосфогипс из обременительного отхода производства в продукцию или, по крайней мере, сырье для производства продукции. Стратегия выбора технологии конверсии фосфогипса должна основываться на требованиях рынка. Следует отметить, что при определении экономической эффективности и рентабельности таких производственных комплексов капитальные вложения и эксплуатационные расходы следует рассчитывать для единого производства фосфорной кислоты и удобрений на ее основе, фосфогипса и продуктов его переработки, а также ряда других выбранных продуктов.
Из приведенных выше результатов работ можно сделать вывод, что технико-экономические показатели процессов использования фосфогипса могут быть значительно улучшены [14-17]. Для этого требуется выполнение значительного комплекса научно-исследовательских, опытных, проектно-конструкторских и технико-экономических работ.

Работа выполнена при финансовой поддержке Европейского сообщества в рамках проектов ECOPHOS (контракт № INCO-CT-2005-013359) и EFENIS (контракт № ENER-FP7-296003).

\section{СПИСОК ЛИТЕРАТУРЫ}

1. Production of Phosphoric Acid. Booklet 4 of 8 . General Product Information on Phosphoric Acid. European Fertilizers Manufactures Association, 1997. Р. 20.

2. Фосфогипс и его использование / Под ред. Эвенчика С.Д., Новикова А.А. М.: Химия, 1990.

3. Виробництво фосфоровмісних мінеральних добрив підприємствами України та їх використання у сільскому господарстві / За ред. Зареченого В.Г. Суми: Університетська книга, 2004.

4. Клемеш Й., Костенко Ю.Т., Товажнянский Л.Л., Капустенко П.А., Ульев Л.М. и др. Применение метода пинч-анализа для проектирования энергосберегающих установок нефтепереработки // Теорет. основы хим. технологии. 1999. Т. 33. № 4. С. 420.

5. Seferlis P., Klemeř J., Bulatov I., Koltsova E., Kapustenko P., Soboleva I. Development of sustainable processes for waste utilisation in phosphoric acid industry // CHISA 2006. Proceedings of the 9th conference on process integration, modelling and optimisation for energy saving and pollution reduction. PRES 4. Prague, 2006. Р. 1154.

6. Товажнянский Л.Л., Капустенко П.А., Ульев Л.М., Болдырев С.А., Арсеньева О.П., Тарновский М.В. Интеграция тепловых процессов на установке первичной переработки нефти АВТ А12/2 при работе в зимнее время // Теорет. основы хим. технологии. 2009. T. 43. № 6. С. 665.

7. Товажняянкий Л.Л., Ведь В.Е., Кощий В.А., Ровенский А.И., Мешалкин В.П., Краснокутский Е.В. Эффективность функционирования очистной системы мобильного комплекса термокаталитического обезвреживания отходов // Теорет. основы хим. технологии. 2011. Т. 45. № 6. С. 648.

8. Мешалкин В.П., Товажнянский Л.Л., Ульев Л.М., Мельниковская Л.А., Ходченко С.М. Энергоресурсоэффективная реконструкция установки нефтепереработки на основе пинч-анализа с учетом внешних тепловых потерь // Теорет. основы хим. технологии. 2012. Т. 46. № 5. С. 648.

9. Ламп В.Н., Абашкина Т.Ф., Бризицкая Н.М. и др. Исследование процесса конверсии фосфогипса в сульфат аммония // Реф. информация НИУИФа. Промышленность минеральных удобрений и серной кислоты. Вып. 247. М.: НИИТЭХИМ, 1983. С. 8.

10. Kuberska J. Rozklad fosfogipsu weglanem sodowym // Chemia stosowana. 1986. V. 30. № 1. P. 113. 
11. Товажнянский Л.Л., Капустенко П.А., Хавин Г.Л., Арсеньева О.П. Пластинчатые теплообменники в промышленности. Харьков: НТУ “ХПИ”, 2004.

12. Arsenyeva O.P., Tovazhnyansky L.L., Kapustenko P.O., Khavin G.L. Optimal design of plate-and-frame heat exchangers for efficient heat recovery in process industries // Energy. 2011. V. 36. № 8. P. 4588.

13. Kapustenko P., Boldyryev S., Arsenyeva O., Khavin G. The use of plate heat exchangers to improve energy efficiency in phosphoric acid production // J. Cleaner Prod. 2009. V. 17. № 10. P. 951.

14. Tovazhnyansky L., Kapustenko P., Ulyev L., Boldyryev S., Arsenyeva $O$. Process integration of sodium hypophosphite production // Appl. Therm. Eng. 2010. V. 30. № 16. P. 2306.
15. Товажнянский Л.Л., Капустенко П.А., Хавин Г.Л. Комплексная переработка фосфогипса с извлечением редкоземельных элементов // Інтегровані технології та енергозбереження. 2008. № 2. С. 73.

16. Товажнянский Л.Л., Капустенко П.А., Бухкало С.И., Перервертайленко А.Ю. Энергосберегающие инженерно-технологические мероприятия в процессах конверсии фосфогипса // Междунар. научнопракт. конф. “Логистика и экономика ресурсосбережения и энергосбережения в промышленности ЛЭРЭП-3-2008”. Казань, 2008.

17. Kapustenko P.A., Perevertaylenko A.Yu., Khavin G.L., Bukhalo S.I., Arsenyeva O.P. Energy saving approaches for processes of phosphogypsum complex conversion // Proc. 18th Int. Congr. of Chemical and Process Engineering CHISA'2008. Praha, 2008. P. 1414. 